\title{
Thin-layer chromatography of hippuric and m-methylhippuric acid in urine after mixed exposure to toluene and xylene
}

\author{
GRAŻYNA BIENIEK AND T WILCZOK
}

From the Institute of Chemistry and Physics, University Medical School of Silesia, Sosnowiec, Poland

ABSTRACT The separation of hippuric and m-methylhippuric acid as toluene and $\mathrm{m}$-xylene metabolites present in urine of people exposed simultaneously to toluene and xylene is described. Chloroform was used for hippuric and m-methylhippuric acid extraction. Satisfactory separation of these metabolites was obtained on TLC plates covered with silica gels and developed in chloroform acetic acid-water (4:1:1); p-dimethylaminobenzaldehyde in acetic acid anhydride was applied to develop the colour. The sensitivity of the method was $6 \mu \mathrm{g}$ hippuric acid per $1 \mathrm{ml}$ urine and recovery was $100 \%$ $( \pm 1)$.

Evaluation of mixed exposure to toluene and xylene may be carried out by measuring the rate of excretion of hippuric acid ${ }^{1}$ and $\mathrm{m}$-methylhippuric acid ${ }^{2}$ in the urine, separating the compounds beforehand. Numerous reported methods ${ }^{3-5}$ of hippuric acid determination afford combined determination of toluene and xylene metabolites. Among methods for determination and separation of the above metabolites, gas chromatography, ${ }^{6-8}$ paper chromatography, ${ }^{910}$ high-speed liquid chromatography, ${ }^{11}$ and thin-layer chromatography ${ }^{10}$ have been described. The method presented in this paper is simple and highly reproducible. Since the reproducibility of results obtained by the method of Ogata $e a^{10}$ was unsatisfactory, the determination of m-methylhippuric acid has been modified by Orłowski ${ }^{9}$ by using paper chromatography where optimal conditions of analysis were described. The accuracy of Orłowski's ${ }^{9}$ method of hippuric and m-hippuric acids estimation is $\pm 3 \%$, yet the development of the chromatogram is timeconsuming. To overcome these difficulties, we have attempted to develop a method of hippuric and $\mathrm{m}$ methylhippuric acids determination in urine by the use of thin-layer chromatography. The problem of determining toluene and xylene metabolites in urine has been detailed by Ogata et al, ${ }^{10}$ Orłowski, ${ }^{9}$ and Burkiewicz and Zielińska. ${ }^{3}$

\section{Material and methods}

The method of determining hippuric and m-methyl-

Received 17 June 1980

Accepted 9 September 1980 hippuric acid concentrations was worked out for standard water solutions within the range of the concentration $0.3-0.4 \mathrm{mg} / \mathrm{ml}$ and later checked on urine samples. Toluene and xylene metabolites were extracted according to the methods of Burkiewicz and Zielińska. ${ }^{3}$ All colour-developing reactions for making identification and quantitative determinations were similar to that described by Ogata et al. ${ }^{10}$ This system has the highest reproducibility among many others for the separation and identification of hippuric and m- or p-methylhippuric acid. Separation was carried out with the use of toluene-acetic acidwater $(100: 50: 2 \cdot 5)$ on silica gel G. In this study, double chloroform extraction of these compounds from urine has been carried out, but the extraction of hippuric and m-methylhippuric acids may be carried out also according to the methods of Ogata et al ${ }^{10}$ and Orłowski. ${ }^{9}$

Adsorbents used-Plates with adsorbents already in situ, silufol $254 \mathrm{UV}$, silufol $254+266 \mathrm{UV}$ (made in Czechoslovakia), as well as chromatographic plates covered with kieselgel G (according to Stahl), silicagel GF 254 (Macherey-Nagel), and silicagel LS $5 / 40 \mu$ were used. The adsorbents on the plates dried at room temperature for 10-15 min were in layers of $0.25 \mathrm{~mm}$. The plates were activated for one hour, dried again at $105^{\circ} \mathrm{C}$, and stored in a desiccator over $\mathrm{CaCl}_{2}$.

Three developing systems and four developing reagents were examined to reach the highest reproducibility and to improve the exactness of determination.

Developing systems-I-chloroform-acetic acid- 
water $(4: 1: 1)$ chloroform layer used after having solvent mixture shaken and separated. II-toluenemethanol-acetic acid (43:9:5). III-light petroleumbenzene-chloroform-methanol-acetic acid (14:2:2:1: 1).

Developing reagents - A p-Dimethylaminobenzaldehyde $(4 \mathrm{~g})$ was dissolved in $100 \mathrm{ml}$ of acetic acid anhydride with $1 \mathrm{~g}$ of sodium acetate. ${ }^{10} \mathrm{~B}$ Pyridineacetic acid anhydride (5:2 v:v). ${ }^{3} \mathrm{C}$ Methyl red in acetic acid anhydride $-1 \%$ solution. D Bromocresolic green-1\% solution.

\section{Procedure}

One millilitre of urine was acidified with two drops of concentrated $\mathrm{H}_{2} \mathrm{SO}_{4}$ and twice extracted with $5 \mathrm{ml}$ chloroform. The extract was concentrated to the volume of $1 \mathrm{ml}$ under reduced pressure. Aliquots of $50 \mu$ were spotted on the activated chromatographic plate-silufol 254 UV and developed with chloroformacetic acid-water $(4: 1: 1)$. The degree of separation of hippuric and m-methylhippuric acids obtained by using the above described adsorbents is presented in table 1 . The solvent was allowed to evaporate, and the plates were sprayed with p-dimethylaminobenz- aldehyde reagent (A), and heated at $135^{\circ} \mathrm{C}$ for three minutes to develop the colour. The azlactones were extracted twice with $2 \mathrm{ml}$ and $1 \mathrm{ml}$ of ethanol, and the absorbance was determined spectrophotometrically at $465 \mathrm{~nm}$ against ethanol as the blank by the use of the low-range Cary $118 \mathrm{C}$ spectrophotometer.

\section{Results}

Table 1 presents the values of $R_{f}$ coefficients for hippuric and m-methylhippuric acid separated on commercial silufol $254 \mathrm{UV}$, silufol $254+366 \mathrm{UV}$ plates, as well as on home-made plates covered with silica gel type LS $5 / 40 \mu$ and silicagel type GF 254 and kieselgel $\mathrm{G}$.

Since p-dimethylaminobenzaldehyde in acetic acid anhydride irritates the mucose membrane and conjuctivae and therefore is noxious to persons in direct contact with this reagent, attemps were undertaken to find other reagents that would give coloured reactions with intensive and stable colouring. The results of the experiments are presented in table 2 .

Stable colouring of the separated compounds was obtained from the application of p-dimethylamino-

Table $1 R_{f}$ coefficients of hippuric acid $(H A)$ and m-methylhippuric acid $(M H A)$ developed under described conditions

\begin{tabular}{|c|c|c|c|c|c|c|c|c|c|c|}
\hline \multirow{3}{*}{$\begin{array}{l}\text { Absorbent } \\
\text { Developing system }\end{array}$} & \multirow{2}{*}{\multicolumn{2}{|c|}{$\begin{array}{l}\text { Silufol } \\
254 \text { UV } \\
\text { Values }\end{array}$}} & \multicolumn{2}{|c|}{$\begin{array}{l}\text { Silufol } \\
254+366 U V\end{array}$} & \multicolumn{2}{|c|}{$\begin{array}{l}\text { Silicagel } \\
\text { LS } 5 / 40_{\mu}\end{array}$} & \multicolumn{2}{|c|}{$\begin{array}{l}\text { Sillicagel } \\
\text { GF } 254\end{array}$} & \multicolumn{2}{|c|}{$\begin{array}{l}\text { Kieselgel G } \\
\text { after Stahl }\end{array}$} \\
\hline & & & & & & & & & & \\
\hline & MHA & HA & MHA & HA & MHA & HA & MHA & HA & MHA & HA \\
\hline $\begin{array}{l}\text { Chloroform-acetic acid- } \\
\text { water }(4: 1: 1)\end{array}$ & 0.89 & 0.64 & 0.49 & 0.41 & 0.45 & 0.37 & 0.37 & $0 \cdot 27$ & 0.45 & 0.33 \\
\hline $\begin{array}{l}\text { Toluene-methanol-acetic } \\
\text { acid }(43: 9: 5)\end{array}$ & 0.61 & 0.57 & 0.46 & $0 \cdot 40$ & NO & NO & NO & NO & 0.45 & 0.32 \\
\hline $\begin{array}{l}\text { Light petroleum-benzene } \\
\text { chloroform methanol-acetic } \\
\text { acid }(14: 2: 2: 1: 1)\end{array}$ & NO & NO & $0 \cdot 36$ & $0 \cdot 30$ & 0.26 & 0.20 & NO & NO & NO & NO \\
\hline
\end{tabular}

NO = Separation of hippuric and m-methylhippuric acid was not obtained.

Table 2 Colour reactions of hippuric and m-methylhippuric acids with the use of various developing systems

\begin{tabular}{|c|c|c|c|c|}
\hline Developing reagent & $\begin{array}{l}\text { A } \\
\text { p-Dimethylaminobenz- } \\
\text { aldehyde reagent }\end{array}$ & $\begin{array}{l}\text { B } \\
\text { Pyridine reagent }\end{array}$ & $\begin{array}{l}\text { C } \\
\text { Methyl red reagent }\end{array}$ & $\begin{array}{l}\text { D } \\
\text { Bromocresol green } \\
\text { solution }\end{array}$ \\
\hline $\begin{array}{l}\text { Chloroform-acetic acid- } \\
\text { water }(4: 1: 1)\end{array}$ & $\begin{array}{l}\text { Orange against light } \\
\text { background stable }\end{array}$ & $\begin{array}{l}\text { Yellow against light } \\
\text { background unstable }\end{array}$ & $\begin{array}{l}\text { White against red } \\
\text { background stable }\end{array}$ & $\begin{array}{l}\text { Yellow against green } \\
\text { background unstable }\end{array}$ \\
\hline $\begin{array}{l}\text { Toluene-methanol-acetic } \\
\text { acid }(43: 9: 5)\end{array}$ & As above & No reaction & As above & $\begin{array}{l}\text { Whole plate covered with } \\
\text { yellow colour }\end{array}$ \\
\hline $\begin{array}{l}\text { Light petroleum-benzene- } \\
\text { chloroform-methanol-acetic } \\
\text { acid }(14: 2: 2: 1: 1)\end{array}$ & As above & No reaction & As above & No reaction \\
\hline $\begin{array}{l}\text { Maximum absorbance of the } \\
\text { colour compound } \mathrm{nm}\end{array}$ & 465 & 363 & Far UV & 420 \\
\hline
\end{tabular}


benzaldehyde as well as methyl red in acetic acid anhydride. Coloured compounds were obtained on chromatograms developed with these reagents in all three developing systems as presented in table 1 . The absorbtion maximum of the compound formed during the reaction of hippuric and m-methylhippuric acid with methyl red in the presence of acetic acid anhydride was in the far UV region. It was shown that p-dimethylaminobenzaldehyde, proposed by Ogata et al, ${ }^{10}$ is still the best developing solution among those tested, forming stable compounds with intensive orange colouring. The above described method of determination was compared with the colorimetric method of hippuric acid determination presented by Burkiewicz and Zielińska, ${ }^{3}$ where the hippuric acid concentration was determined in the urine of people exposed to toluene.

One has to take into consideration that the method described by Burkiewicz and Zielińska ${ }^{3}$ is proposed for hippuric acid determination only. The results are shown in the figure. A high correlation coefficient

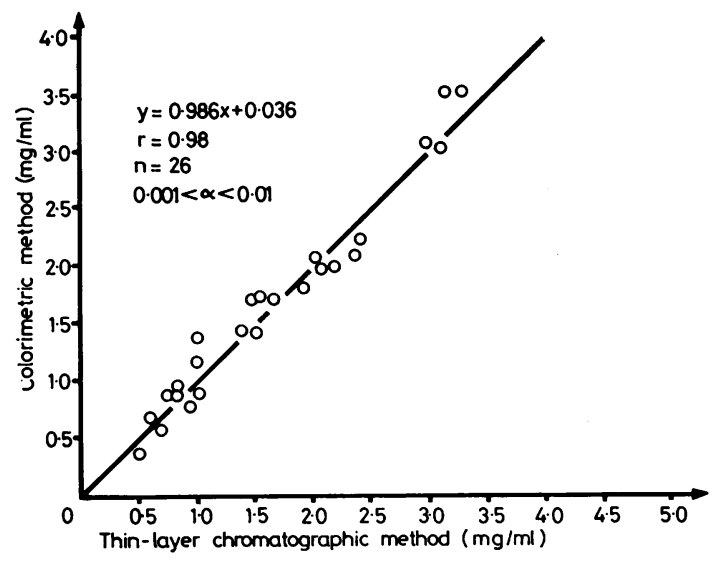

Comparison of hippuric acid concentrations in urine analysed by thin-layer chromatography $v$ colorimetric method.

( $\mathrm{r}=0.988 \mathrm{n}=26$ ) was obtained when hippuric acid was analysed in urine samples by the use of both independent methods, the colorimetric one and the one proposed in this paper; the correlation was statistically significant $(0.01>\alpha>0.001)$.

\section{Discussion}

The best separation of hippuric and m-methylhippuric acids was achieved using chloroform-acetic acid-water $(4: 1: 1)$ because of the highest differences of the $R_{\mathbf{f}}$ values. This system can be applied for all adsorbents listed in table 1 . The separation of hippuric and m-methylhippuric acids was most effective on silufol plates type silufol $254+366 \mathrm{UV}$. Similar results were achieved when both acids were separated on silicagel G (after Stahl) and when the developing system of chloroform-acetic acid-water $(4: 1: 1)$ or toluene-methanolacetic acid $(43: 9: 5)$ was used. It was shown that the best developing reagent among those tested is still that proposed by Ogata et al ${ }^{10}$; p-dimethylaminobenzoic acid gives an intense colour reaction and is stable for several days.

The described separation procedure of hippuric and m-methylhippuric acids enables the selective determination of metabolites derived from toluene and m-xylene to be made when workers are professionally exposed to both compounds simultaneously. The exactness of hippuric acid and m-methylhippuric acid determination is $99 \% \pm 3.4 \%$ by $6.0 \mu \mathrm{g} / \mathrm{ml}$. This procedure may be applied therefore for low quantities of analysed metabolites.

\section{References}

1 Wilczok T, Bieniek G. Urinary hippuric acid concentration after occupational exposure to toluene and its use as biological exposure test. Br J Ind Med 1978;35:330-4.

${ }^{2}$ Seńczuk W, Orłowski J. Absorption of m-xylene vapours through the respiratory tract and excretion of $\mathrm{m}$ methylhippuric acid in urine. Br J Ind Med 1978;35:50-6.

${ }^{8}$ Burkiewicz C, Zielińska H. Metoda oznaczania kwasu hipurowego u ludzi narażonych na toluen. Med Pracy 1972;23:487-97.

${ }^{4}$ Sinha SN, Gabrieli ER. A simple method for simultaneous determination of benzoic and hippuric acids in biological fluids. Clin Chim Acta 1968;19:313-7.

${ }^{5}$ Mikulski P, Wiglusz R. A simple micromethod of determination of hippuric acid in the urine. Bull Inst Marit Med Gdańsk 1970;21:129-38.

${ }^{6}$ Buchet IP, Lauwerys RP. Measurement of urinary hippuric and $\mathrm{m}$-methylhippuric acids by gas chromatography. $\mathrm{Br}$ J Ind Med 1973;30:125-8.

${ }^{7}$ Kira S. Measurements by gas chromatography of urinary hippuric acid and methylhippuric acid as indices of toluene and xylene exposure. Br J Ind Med 1977;34: 305-9.

${ }^{8}$ Caperos IR, Fernandez IG. Simultaneous determination of toluene and xylene metabolites in urine by gas chromatography. BrJ Ind Med 1977;34:229-33.

9 Orlowski J. Kolorymetryczna metoda oznaczania kwasu m-metylhipurowego w moczu oraz przebieg wydalania. Bromatologia i Chemia Toksykologicina 1974;7:87-91.

${ }^{10}$ Ogata M, Tomokuni K, Takatsuka Y. Quantitative determination in urine of hippuric acid and m- or p-methylhippuric acid, metabolites of toluene, and $\mathrm{m}$ - or p-xylene. Br J Ind Med 1969;26:330-4.

${ }^{11}$ Matsui H, Kasao H, Imamura S. Quantitative determination of hippuric and m-methylhippuric acids in urine by high-speed liquid chromatography. Br J Ind Med 1977; 34:310-3. 